\title{
Analysis of the Impact of the Epidemic on the Technology-related Industry by Fama-French Five-factors Model
}

\author{
Guoxu Zhou ${ }^{1, *}$ \\ ${ }^{1}$ International College, Hailiang Foreign Language School, Zhuji City,311814, China \\ *Corresponding author. Email:guanghua.ren@gecacdemy.cn
}

\begin{abstract}
Before and during the epidemic, all major industries were hit and affected to a certain extent. In this paper, the FamaFrench five-factor model is used as the basic model. The data from the French database and the method of linear regression are adopted to analyze the impact on the technology industry. Three industries, chip, software, and hardware, are adopted as the research objects. In the analysis of factor changes, it is found that the model is suitable for the analysis of the technology market, and there is no abnormal existence. The sensitivity of the technology industry as a whole to the changes in supply and demand caused by the epidemic is increasing significantly. As for the market, investors preferred to invest in companies with strong profitability. The technology market is subdivided into hardware and software sectors. The epidemic situation has a certain inhibitory effect on the hardware industry, while it gives a certain development space to the software industry. According to the structural bull market of Nasdaq, the software industry is more in favor of investing in high market capitalization companies. For the technology industry as a whole, the shifts in investors and market preferences have not been significant.
\end{abstract}

\section{Keywords: Fama-French model, Covid-19, Technology industry, Asset Pricing}

\section{INTRODUCTION}

In 2020, the COVID-19 outbreak spread around the world, causing severe shocks to financial markets. The global stock market has undergone a very drastic adjustment. The US stock market has suffered several circuit breakings in a few weeks, with the Dow Jones Industrial Average falling from close to 30,000 to around 20,000 at one time. Volatility in the financial market has soared significantly, and the market has also seen the rare phenomenon of risky assets falling in tandem with safe assets. The main reason was the overseas-expected spread of COVID-19, which changed investors' risk appetite and expectation and triggered a liquidity run in the financial market. And as people adapted to COVID-19, "Lockdowns have driven a wedge between the consumption of services and goods, generating additional demand from both households and governments looking to stimulate activity while minimizing the Virus get spread ", which increase in demand has, in turn, led to a structural bull market in financial markets for all commodity stocks. The Dow Jones, Standard \& Poor's 500, and NASDAQ all hit new highs in April. While concerns about COVID-19 have eased, the stock market has been on edge this year because of bond yields, inflation, and high valuations for technology and growth companies. However, March was the best month for stocks since November, with big tech stocks rebounding and a historically strong April for stocks getting off to a strong, profitable start. Market history suggests that once a bull market starts, it can last for years, though the gains moderate. Analysts at Goldman Sachs agree that the structural bull market will continue. In this study, the significance of capital asset pricing comes into being to help investors maximize profits. In the post-epidemic era, capital pricing is particularly effective because of the increased instability of risk. It enables investors to evaluate and select financial assets with competitive quotations according to absolute risk rather than total risk. In the financial field, it is also very important. It tries to explain the price or value of the asset that will be paid in the future under the condition of uncertainty. In this case, the asset usually refers to the financial instrument or some security. The price is the price of its market equilibrium: the price determined by the market demand and supply. 
This is also a further step in the study of pricing in the field.

In the description of capital asset pricing, CAPM and Fama French are more commonly used. In selecting models, Ravi and Wang assumed that CAPM has conditional meaning, that is, beta value and market risk premium change over time. They included human capital return in total wealth return. Further, They explained the cross-section of average return Finally, the conditional capital asset pricing model is used to explain the ability of cross-sectional changes in average returns of large stock portfolios[1]. Javier, based on the behavior of investors' mean-variance, studies the feasibility of D-CAPM and CAPM in emerging stock markets through semi-variance of returns (an alternative risk measure) and $\mathrm{D}-\mathrm{CAPM}($ an alternative pricing model) The resulting evidence clearly supports lower BETA and D-CAPM and higher CAPM [2]. To get a more realistic picture of the epidemic's impact, Aarne explored the impact of the COVID-19 pandemic on financial markets by examining the significance of the difference in stock returns between low and high BETA values among the five CAPM indicators. The model attempts verified the effectiveness of CAPM under abnormal conditions, and the conclusion was that CAPM did not apply to the five indicators selected during the COVID-19 pandemic. These findings further support the view that pre-existing CAPM is ineffective in developed markets [3]. Therefore, it is clear that CAPM has market value but does not fit the context of the epidemic we want to consider. To further confirm this idea, Paliienko et al. studied portfolio evaluation during the transition from the single-factor CAPM model to the Fama-French five-factor model (FF5F). They found the advantages of the latter The controversial use of securities investors in different countries is discussed. The characteristics of the statistical stratification method for grouping stock portfolios in the FF5F model are revealed. The FF5F model provides more use and improves the validity of the results of portfolio analysis. They also vary from RMW and CMA in part The research confirms the application of these methods in testing the Fama-French five-factor model of blue-chip stocks[4]. However, the application ability of FF5F in different markets should be examined after the model is clearly used Stulz constructed an intertemporal international asset pricing model, which assumed that different consumption opportunity sets existed in different countries. The results showed that, worldwide, the actual expected excess return of risky assets was proportional to the covariance of asset returns, and the covariance changed with the change of the actual consumption rate (the consumption in the real world was not In general, this is equivalent to a basket of goods consumed by all investors.) The model does not discourage international investment, but it does contradict the predictions of earlier models, which seem to imply that asset markets are internationally fragmented[5]. Foye, on the other hand, first tested the performance of the new FamaFrench five-factor model across a wide range of emerging markets, using a broad sample of 18 countries from three different regions by assessing the ability of the new Fama-French five-factor model to describe the returns of emerging market equities And concluded that in eastern Europe and Latin America, the performance of the five factors model is significant. However, profitability or investment premium with Asia factors is difficult to distinguish. The five factors model does not describe the region's stock returns [6]. For the largest economy in the Asian region, $\mathrm{Hu}$ et al. studied the cross-section of size factor and value factor of stock market returns in China. They found a significant effect of scale. Studies show that the average premium of a market portfolio and a zero-cost high-low (HML) portfolio is statistically different from zero. In time series regression and the Fama Macbeth cross-section test, SMB is the strongest factor explaining the crosssection of Chinese stock returns. Their results contradict some existing studies on the demonstrative value effect. They show that the difference comes from the extreme conditions in the first few months of the stock market when the stock market is small and volatile. With longer sample time and appropriate volatility adjustments, their effects become irrelevant [7].With further analysis, Xiong et al. took the relationship between stock return and risk as the research focus and focused on the relationship between individual synthetic risk and stock return. They selected all A-shares of Shanghai and Shenzhen stock markets on January 4, 2000. December 31, 2015, with A sample of 3,871 trading days, using rolling window analysis and Fama-French five-factor model to calculate characteristic volatility, empirical results show a negative correlation between idiotrait risk and stock returns in China's stock market. In addition, they construct a high-low idiotrait risk portfolio and verify that there is a significant economic relationship between idiotrait risk and stock returns [8].

In terms of practical application, Blitz et al. proposed five potential problems around the FF5F model from the perspectives of low-risk anomalies, dynamics, the robustness of new factors, economic logic, and asset pricing debates. To provide the market with a model that retains the five-factor model's advantages and solves five problems [9]. To fit the research direction in the field of science and technology, this paper referred to the relevant research in the field of technology by Deng et al. They studied the patentrelated indicators in the field of technology to reflect the potential and growth of technology companies. They tested the index's ability to predict stock returns on a price-to-book basis. They found that the amount of research a company conducts and how closely it is involved in subsequent innovation and research and 
development correlates closely with the performance of R\&D-intensive companies in capital markets [10].

Based on the Fama-French five-factor model and the principle of linear regression, this paper selects chip, software, and hardware industries as the technology industry representatives. Analyze the change amount of the overall factors of the technology industry before and during the epidemic, then analyze the specific meaning behind the change of different factors, and study the impact of the technology industry, to get the change of the connection between the technology industry and market investment preference.

\section{METHOD}

\subsection{Capital Asset Pricing Model (CAPM)}

As one of the forecasting models based on the expected return equilibrium of risky assets, CAPM describes the formation of market equilibrium state under the condition that investors all adopt Markowitz's theory for investment management and expresses the theoretical relationship between the expected return and expected risk of assets in a simple linear relationship [11]. In other words, there is a positive correlation between the expected rate of return of an asset and $\beta$ value, a measure of the risk of the asset.

$$
\mathrm{ER}_{\mathrm{i}}=\mathrm{R}_{\mathrm{f}}+\beta_{\mathrm{i} *}\left(\mathrm{ER}_{\mathrm{m}}-\mathrm{R}_{\mathrm{f}}\right)
$$

Where the $\mathrm{ER}_{\mathrm{i}}$ is the expected rate of return of asset $\mathrm{i}, \mathrm{R}_{\mathrm{f}}$ is the risk-free rate of interest, the typical risk-free rate of return is 10 - year US government bonds. $\beta_{\mathrm{i}}$ is the Beta coefficient, namely the systemic risk of asset $i$, and $\mathrm{ER}_{\mathrm{m}}$ is the expected market rate of return.

If an equity investor takes an extra risk, he will need to earn a corresponding premium over the risk-free rate of return. The equity market premium is equal to the expected return of the market minus the risk-free return. The security risk premium is the product of the stock market premium and a beta factor.

$$
\begin{gathered}
\text { equity market premium }=\left(E R_{m}-R_{f}\right) \\
\text { Risk Premium }=\beta i^{*}(E R m-R f)
\end{gathered}
$$

\subsection{Fama-French Five-factor Model}

Fama-French Five-factor Model Theory (FF5F) was proposed by Fama and French in 2015 [12]. Compared with the three-factor model constructed in 1993 [13], the two profitability and investment factors were added. There is evidence that the three-factor model is inadequate for expected returns because its three factors ignore many variations in average returns related to profitability and investment. The empirical test of the five-factor model aims to explain the average return of a portfolio that generates large spreads in terms of size, book value, profitability, and investment.

$$
\mathrm{R}_{\mathrm{it}}-\mathrm{R}_{\mathrm{Ft}}=\mathrm{a}_{\mathrm{i}}+\mathrm{b}_{\mathrm{i}} *\left(\mathrm{R}_{\mathrm{Mt}}-\mathrm{R}_{\mathrm{Ft}}\right)+\mathrm{s}_{\mathrm{i}} * \mathrm{SMB}_{\mathrm{t}}+\mathrm{h}_{\mathrm{i}} * \mathrm{HML}_{\mathrm{t}}+\mathrm{r}_{\mathrm{i}} * \mathrm{RMWt}+\mathrm{c}_{\mathrm{i}} * \mathrm{CMA}_{\mathrm{t}}+\mathrm{e}_{\mathrm{it}}
$$

The $\left(\mathrm{R}_{\mathrm{Mt}}-\mathrm{R}_{\mathrm{Ft}}\right)$ is the excess return of the market. It is the return on the value-weighted market portfolio. SMB returns on a diversified portfolio of small-cap stocks minus the return on a diversified portfolio of big-cap stocks. HML is the difference between the returns on diversified portfolios of stocks with high and low Bookto-Market ratios. To explain the factor more specifically, we need to derive the formula.

$$
\mathrm{m}_{t}=\sum_{\tau=1}^{\infty} E\left(d_{t+\tau}\right) /(1+r)^{\tau}
$$

$\mathrm{mt}$ is the stock price at time $\mathrm{t}, \mathrm{E}(\mathrm{dt}+\tau)$ is the expected dividend per share at time $t+\tau$, and $r$ (approximately) is the long-run average expected stock return, or more accurately, the internal rate of return on the expected dividend.

Then, it can be changed to the following one.

$$
M_{\mathrm{t}}=\sum_{\tau=1}^{\infty} \mathrm{E}\left(\mathrm{Y}_{\mathrm{t}+\tau}-d B_{t+\tau}\right) /(1+r)^{\tau}
$$

$\mathrm{Yt}+\tau$ is the total return on equity in $\mathrm{t}+\tau$ period, while $\mathrm{dBt}+\tau=\mathrm{Bt}+\tau-\mathrm{Bt}+\tau-1$ is the change in total book equity. Divided by time $t$, book equity is equal to

$$
\frac{M_{\mathrm{t}}}{B_{t}}=\frac{\sum_{\tau=1}^{\infty} \mathrm{E}\left(\mathrm{Y}_{\mathrm{t}+\tau}-d B_{t+\tau}\right) /(1+r)^{\tau}}{B_{t}}
$$

In Equation (7), fixing everything except the current value of the stock, $\mathrm{M}_{\mathrm{t}}$, and the expected return on the stock, $r$. Then the lower value of $\mathrm{M}_{\mathrm{t}}$, or equivalent to a higher book-to-market equity ratio $B_{t} / M_{t}$, implies a higher expected return. Moreover, RMW is the difference between the returns on diversified portfolios of stocks with robust (high and steady) and weak (low) profitability. CMA is the difference between the returns on diversified portfolios of the stocks of low and high investment firms, which we call conservative and aggressive. Here, low/high investment means reinvestment ratio is low/high.

\section{RESULTS}

In 2021, as we mentioned earlier, there was a Nasdaq structural bull market in the financial markets, while in the stock market, the gains in tech stocks have been a measure of the market's direction. Therefore, this study focuses on the technology industry and selects the industry data of CHIPS, Software, and Hardware from the French Data Library as the basis. In addition, multiple linear regression (MLR) was adopted to derive 
the five-factor models for the three industries in 2019 and 2020, respectively. The database contains portfolio performance and returns data for three industries. To further investigate the outbreak's impact, data from May 2019 to February 2020 (pre-pandemic) and March 2020 to December 2020 (during the pandemic) were selected for comparison. Moreover, to ensure the study's accuracy, a significance of $5 \%$ was used as the measurement standard. The obtained results are shown in three tables, as follows:

Table 1. Multiple regression results of the analysis of chips market

\begin{tabular}{ccccc}
\hline \multirow{2}{*}{ Item } & \multicolumn{2}{c}{ Before Covid-19 } & \multicolumn{2}{c}{ During Covid-19 } \\
\cline { 2 - 5 } & Coefficients & $\mathrm{t}$ Stat & Coefficients & $\mathrm{t}$ Stat \\
\hline Intercept & 0.070 & 1.615 & 0.034 & 0.617 \\
Mkt & 1.362 & 26.425 & 1.236 & 47.944 \\
SMB & 0.115 & 1.188 & 0.031 & 0.465 \\
HML & -0.254 & -2.563 & -0.573 & -10.634 \\
RMW & 0.786 & 4.840 & 0.487 & 4.411 \\
CMA & 0.128 & 0.672 & 0.640 & 4.545 \\
\hline
\end{tabular}

As shown in Table 1, Intercept was not significant before and after the epidemic, and there was no anomaly. The coefficients of Mkt before and after the epidemic were significantly greater than 1 , indicating that the sensitivity of the technology industry is greater than that of the overall market. HML is significant and less than 0 after the outbreak, indicating that the investors prefer to invest in a growth stock. RMW is significant and greater than 0 , indicating that investors prefer companies with good profitability. The SMB factor is invalid and does not affect it. However, the CMA factor changed from non-significant to significant before and after the epidemic. It was greater than 0 , which had an inhibitory effect on the investment in the CHIPS industry.

Table 2. Multiple regression results of the analysis of hardware market

\begin{tabular}{ccccc}
\hline \multirow{2}{*}{ Item } & \multicolumn{2}{c}{ Before Covid-19 } & \multicolumn{2}{c}{ During Covid-19 } \\
\cline { 2 - 5 } & Coefficients & $\mathrm{t}$ Stat & Coefficients & $\mathrm{t}$ Stat \\
\hline Intercept & -0.101 & -1.682 & -0.039 & -0.512 \\
Mkt & 1.292 & 18.077 & 1.047 & 29.352 \\
SMB & 0.160 & 1.196 & 0.097 & 1.058 \\
HML & -0.033 & -0.241 & -0.105 & -1.412 \\
RMW & -0.080 & -0.355 & 0.076 & 0.498
\end{tabular}

$\begin{array}{lllll}\text { CMA } & 0.403 & 1.521 & 0.489 & 2.512\end{array}$

According to Table 2, Intercept is not significant before and after the epidemic, and there is no anomaly. Mkt before and after the epidemic was significantly greater than 1 , indicating that the sensitivity of the technology industry is greater than that of the overall market. HML was not significant, RMW was not significant. The SMB factor is invalid and does not affect it. However, the CMA factor changed from nonsignificant to significant before and after the epidemic. It was greater than 0 , which had an inhibitory effect on the investment in the HARDWARE industry.

Table 3. Multiple regression results of the analysis of software market

\begin{tabular}{ccccc}
\hline \multirow{2}{*}{ Item } & \multicolumn{2}{c}{ Before Covid-19 } & \multicolumn{2}{c}{ During Covid-19 } \\
\cline { 2 - 5 } & Coefficients & $\mathrm{t}$ Stat & Coefficients & $\mathrm{t}$ Stat \\
\hline Intercept & 0.005 & 0.200 & -0.015 & -0.421 \\
Mkt & 1.118 & 39.193 & 1.074 & 65.443 \\
SMB & -0.120 & -2.242 & -0.136 & -3.237 \\
HML & -0.365 & -6.659 & -0.298 & -8.681 \\
RMW & 0.052 & 0.581 & 0.188 & 2.670 \\
CMA & -0.867 & -8.194 & -0.778 & -8.683 \\
\hline
\end{tabular}

Besides, Table 3 reveals that Intercept is not significant before and after the epidemic, and there is no anomaly. Mkt before and after the epidemic was significantly greater than 1 , indicating that the sensitivity of the technology industry is greater than that of the overall market. SMB is significant and less than 0 and tends to favor large market cap companies. HML is significant and less than 0 , indicating that the institutions prefer to invest in a growth stock. RMW goes from non-significant to significant, and the value is greater than 0 , indicating that investors prefer companies with good profitability. CMA was significant before and after the epidemic, and less than 0 , indicating a certain market opportunity.

\section{DISCUSSION}

\section{1. $M K T$}

For the three industries, the values of Mkt before and after the epidemic are significant and greater than 1 , indicating that the apparent sensitivity of the technology industry is greater than that of the overall market. And the values of Mkt increased to different degrees. This means that these sectors are much more sensitive or volatile than markets in the pandemic. The 
semiconductor market, the most important for hardware and chips, has been volatile and riddled with supplychain shortages that can be daunting, from the strike of the three major European unions at ST to the rising prices caused by wafer shortages, global shortages, and price increases at the five major MCU plants. As a result of the market supply and demand, the relationship is not equal, further aggravating these two industries' turbulence. For the software industry, part of the volatility is due to the changes in the hardware market and chip market, and the other part is due to the rapid growth of the software industry. This unusual growth rate also brings a certain degree of volatility. Taking the Chinese market, for example, due to the epidemic's impact, enterprises could not resume work, so many enterprises changed their office to network offices. Therefore, the two types of apps, enterprise applications and e-government affairs saw the largest year-on-year growth, with about 200 million each. In third place was the short video industry, which grew by 180 million from the same period last year [14]. Therefore, such a huge market demand makes the software market quickly become a large range of fluctuations, which is just for apps, not counting the growth in demand for other types of software.

\section{2. $S M B$}

In the SMB factor, the software industry was significantly and less than 0 before and during the epidemic. That means the market is biased toward larger companies. In the SMB factor, only the software industry was significantly and less than 0 before and during the epidemic. That means the market is biased toward larger companies, closely related to the structural bull market in the Nasdaq that we mentioned earlier. The companies with the largest market capitalization in the U.S. are Apple Inc., Microsoft Corp., Amazon Inc., Google Inc., and Facebook Inc. The top five high-value companies are all technologysoftware companies, which indicates that the financial stock market favors high-value companies in the software category more, which directly supports the results of the SMB factor. As for the chip and hardware markets, the SMB factor is not significant, which means there is no actual effect on market preference, which means that selective investment in hardware companies is not entirely based on market capitalization.

\subsection{HML}

From the perspective of the HML factor, the values of HML are significant and less than 0 for both chip and software industries, which means that the market tends to choose growth stocks for these two industries. In other words, the market is more willing to invest in stocks with long-term sustainable earnings. This is in line with the potential growth of the chip and software markets. Particularly, for example, memory chips of the chip industry, the Global Memory Chip Market was valued at 305.89 Million USD in 2020 and will grow with a CAGR of $1.41 \%$ from 2020 to 2027 [15]. That's a pretty solid growth tendency, and it applies to other chip industries as well. The existence of such room for growth boosts the value of potential growth stocks in the industry. The software numbers are even more striking. In 2020, the global business software and services market size was $\$ 389.86$ billion. It is expected to expand at a compound annual growth rate (CAGR) of $11.3 \%$ from 2021 to 2028 . Therefore, it has the same characteristics as the chip market, and investors and the market are more willing to invest in these potential growth stocks.

But for the hardware market, the HML factor is not significant. It also means the market doesn't favor growth stocks. Through analysis, one of the reasons that can be reflected in that the market may have been in a saturated state or a stage of lack of development momentum. The market may be limited by technical capabilities or space for growth, so it may not like stocks in such sectors.

\section{4. $R M W$}

The profitability factor has the biggest difference among the three markets. In the chip industry, both before and during the epidemic were significant and greater than 0 . It is transformed from not significant before the epidemic to significant and greater than 0 in the epidemic for the software industry. This means that the market favors companies with strong profitability in both industries. But the difference is that there has been a big shift in RMW in the software market.

It indicates that the market investment in the software industry before the epidemic did not focus on the perspective of profitability but paid more attention to the profitability in the middle of the epidemic. And this shift is being driven by the enormous needs of the epidemic. When analyzing the massive expansion of the demand for the software market due to the epidemic in Mkt, such expansion demand brings more capital inflow. Huge demand means huge profits, and investors in the old market tend to focus their investments on more profitable companies. For the chip industry, as R\&D investment costs occupy a high ratio of income to income, investors are bound to take profitability as the first consideration to prevent excessive losses. As for the hardware market, the market is relatively dispersed, and the risk concentration is not as high as that of the chip industry. Profitability is not taken into account completely, so it is not significant. 


\section{5. $C M A$}

The CMA describes investment level risk. For the hardware and chip markets, the values of CMA have changed from insignificant to significant during the selected period, and the value is greater than 0 . This means that the epidemic has a certain dampening effect on investment in the chip and software industries.

For the hardware and chip markets, the values of CMA have tended to be significant after the epidemic, and the value is greater than 0 . This means that the epidemic has a certain inhibiting effect on the investment in the chip and software industries, and the reinvestment rate has decreased. The decline in the proportion of investment is due to the financial impact of the epidemic on enterprises in the industry. The epidemic had a huge impact on companies' cash flow in the industry, which in turn affects the decisions of investors and the market. The return on the reinvestment rate will be reduced, partly due to the shrinking of the market and the reduction of market opportunities caused by the epidemic.

The coefficient of the software industry is significant and less than 0 before and during the epidemic, which means that the market reinvestment ability is essential for the investors. It is probably due to the market opportunity generated behind the explosive demand of the software market, which further boosts the investment.

\section{CONCLUSION}

Through the above analysis and the prediction of the reasons for the change, it can be concluded that the change in investment preference of the science and technology industry in the epidemic is not obvious. Further analysis shows that the technology industry can be divided into software and hardware sectors through changing investment preferences. In the epidemic, the market has inhibited the investment behavior of the hardware industry, while the software industry has a certain investment space. This can be confirmed in combination with the structural bull market in the Nasdaq. For the technology industry, the increased sensitivity is mainly due to short-term changes in supply and demand, which may mean that investment behavior in the technology market will increase to a certain extent in the future.

\section{REFERENCES}

[1] Jagannathan, R., \& Wang, Z. (1996). The conditional CAPM and the cross-section of expected returns. The Journal of Finance, 51(1), 353.

[2] Estrada, J. (2002). Systematic risk in emerging markets: the D-CAPM. Emerging Markets
[3] Airinen, A. (2021). Testing the validity of the Capital Asset Pricing Model during the Covid-19 pandemic: A comparison between pre-pandemic and pandemic periods.

[4] Paliienko, O., Naumenkova, S., \& Mishchenko, S. (2020). An empirical investigation of the FamaFrench five-factor model. Investment Management and Financial Innovations, 17(1), 143-155.

[5] Stulz, R. (1981). A model of international asset pricing. Journal of financial economics, 9(4), 383406.

[6] Foye, J. (2018). A comprehensive test of the FamaFrench five-factor model in emerging markets. Emerging Markets Review, 37, 199-222.

[7] Hu, G. X., Chen, C., Shao, Y., \& Wang, J. (2019). Fama-French in China: size and value factors in Chinese stock returns. International Review of Finance, 19(1), 3-44.

[8] Xiong, X., Yongqiang, M., Ran, L. I., \& Dehua, S. H. E. N. (2017). Idiosyncratic Volatility and Stock Returns: A Fama-French Five-Factor Model Perspective. Journal of Systems Science and Mathematical Sciences, 37(7), 1595.

[9] Blitz, D., Hanauer, M. X., Vidojevic, M., \& Van Vliet, P. (2018). Five concerns with the five-factor model. The Journal of Portfolio Management, 44(4), 71-78.

[10] Deng, Z., Lev, B., \& Narin, F. (1999). Science and technology as predictors of stock performance. Financial Analysts Journal, 55(3), 20-32.

[11] E. F. Fama, and K. R. French, "Common risk factors in the returns on stocks and bonds," Journal of Financial Economics, vol. 33, issue 1, pp. 3- 56, 1993.

[12] E. F Fama, and K. R. French, "A five-factor asset pricing model," Journal of Financial Economics, vol 116, issue 1, pp. 1-22, 2015.

[13] E. F Fama, and K. R. French, "Size and book-tomarket factors in earnings and returns," The Journal of Finance, vol. 50, issue 1, pp. 131-155, 1995.

[14] Zhiyan Consulting Group(2021). Market Development Potential and Investment Profit Analysis Report of China Software Industry (20212027).

[15] Absolute Reports corp.(2021). Global and Regional Memory Chip Industry Status and Prospects Professional Market Research Report Standard Version(2021-2027). 